\title{
SEEPAGE FAILURE ANALYSES OF SANDY GROUND USING A LIQUEFACTION ANALYSIS METHOD BASED ON FINITE DEFORMATION THEORY
}

\author{
T. Kodaka, F. Oka and R. Morimoto \\ Department of Civil Engineering, Kyoto University \\ Yoshida Hon-machi, Sakyo-ku, Kyoto, Japan \\ kodaka@nakisuna.kuciv.kyoto-u.ac.jp
}

\begin{abstract}
Most of seepage failure problems can be classified as liquefaction problem, because effective stresses of sand deposits near/at failure state statically come close to zero. It is, therefore, difficult to predict the seepage failure using conventional deformation analysis methods for saturated soil. In the present paper, a newly developed liquefaction analysis method, which is based on the finite deformation theory, is applied to seepage failure problems. Firstly, 1-D unsteady seepage problem is discussed. Numerical solutions under various initial and boundary conditions are compared with analytical solutions based on the one-dimensional elastic consolidation theory. Secondary, 2-D classical seepage failure problem of horizontal ground with an embedded sheet pile is discussed. It is found that a proposed analysis method can quantitatively explain the distributions of the pore water pressure and the mean effective stress in sand deposit during the unsteady seepage flow until failure, but we need further study to accurately predict the deformation.
\end{abstract}

\section{KEYWORDS}

Unsteady seepage flow, Seepage failure, Liquefaction, Finite element method, Finite deformation theory, Effective stress based analysis

\section{INTRODUCTION}

Seepage failure problems, which are including piping, quick sand, boiling and so on, are typical 3-D problems with large deformations. Furthermore sand near/at failure state due to seepage force is almost liquefied. It is, therefore, difficult to predict the seepage failure using a conventional soil-water coupling deformation analysis method. Asaoka and Kodaka (1992) proposed the seepage failure analysis method using a soil-water coupling rigid plastic finite element method. That analysis was able to predict a limit load and a plastic flow at limit state as well as excess pore water pressure and effective stress distributions. Oka et al. (1994a) applied a newly developed elasto-plastic deformation analysis to seepage failure problem on the way to development of the liquefaction analysis method. Oka et al (1994b) proposed a two-dimensional effective stress based liquefaction analysis method, i.e. LIQCA-2D, which is based on the infinitesimal strain theory. Taguchi et al. (1997) expanded the liquefaction analysis to three-dimensional analysis code LIQCA-3D, and succeeded to analyze the behavior of liquefied ground during Hyogoken Nambu 
earthquake. Oka et al. (2001) newly formulated an effective stress based liquefaction analysis code LIQCA-FD, which is based on the finite deformation theory, in order to prediction the behavior of liquefied ground with large deformation such as the quay wall structures during strong earthquake. In this paper, we would like to concern that LIQCA-FD can apply to seepage failure problems. Both one-dimensional unsteady seepage flow problem and two-dimensional seepage failure problem are studied as first step. We will be concerned with practical three-dimensional seepage failure problem in the future.

\section{LIQUEFACTION ANALYSIS BASED ON FINITE DEFORMATION THEORY}

In this section, the numerical scheme of LIQCA-FD will be summarized. The details should be referred to Oka et al. (2001). The governing equations for soil - water coupling problem are given by adopting the $\mathrm{v}$ (velocity) - $\mathrm{p}$ (pore pressure) formulation.

$$
\rho a_{i}=S_{j i, j}+\rho b_{i}
$$

\section{(Equation of motion)}

$$
\hat{T}_{i j}^{\prime}=C_{i j k l}^{E P} D_{k l}
$$

\section{(Constitutive equation)}

$$
\rho^{F} \dot{D}_{i i}-p_{, i i}-\frac{\gamma_{w}}{k} D_{i i}=0
$$$$
\text { (Continuity equation) }
$$$$
T_{i j}=T_{i j}^{\prime}+p \delta_{i j}
$$

\section{(Effective stress concept)}

where $\rho$ and $\rho^{F}$ are the mass densities of saturated sand and pore water, respectively, $\gamma_{w}$ is the unit weight of pore water, and $k$ is the coefficient of permeability. $S_{i j}$ is the nominal stress tensor and $\hat{T}_{i j}^{\prime}$ is the Jaumann rate of effective Cauchy stress tensor $T_{i j}^{\prime} . a_{i}$ and $b_{i}$ are acceleration vector and body force vector, respectively. $D_{i j}$ is the stretching tensor and $p$ is the pore water pressure. $\delta_{i j}$ is the Kronecker's delta. $C_{i j k l}^{E P}$ is the elasto-plastic stiffness tensor, which was described by Oka et al. (1999) and then expanded to the finite deformation theory by Oka et al. (2001). Finite element method and Newmark $\beta$ method are used for the space and time descretization of governing equations, respectively. 20-nodes rectangular parallelepiped isoparametric element is used for soil skeleton and 8-nodes rectangular parallelepiped isoparametric element is used for the pore water pressure. Up-dated Lagrangian method is also used to update current state. In the case of seepage failure analysis, the surface load increment concomitant with a raising water head is applied and real-time water pressures are simultaneously prescribed at the nodes on the surface of upstream sand deposit. Although the seepage failure problem is quasi-static problem, the complex nonlinear calculation near/at liquefaction state can be stably executed in the proposed dynamic scheme. It is due to the viscous damping and dynamic relaxation effects.

\section{ONE-DIMENSIONAL UNSTEADY SEEPAGE PROBLEM}

It will be useful to discuss a one-dimensional unsteady seepage problem, before we show the multi-dimensional seepage failure problem. Because the accuracy prediction of unsteady seepage field is very important for the analysis methods used for the seepage failure problem. In this section, let us discuss an experiment concerned with the one-dimensional unsteady seepage problem, which is illustrated as in Figure 1. Two cylinders are connected each other by a tube with a valve at bottom side. In one cylinder, sand is submerged in the water and the other cylinder is a water tank. Seepage force is applied due to the water head difference between two cylinders. Typical four cases can be considered as follows; Case I: instantaneous loading from top surface, Case II: instantaneous loading from bottom surface, Case III: increasing loading from top surface, and Case IV: increasing loading from bottom surface. The loading from top surface means that the water head of the cylinder containing sand column is higher than the other cylinder. In that case, the direction of the seepage force in the sand column is down side. On the other hand, the loading from bottom surface means that the water head of the cylinder containing sand column is lower than the other cylinder. 


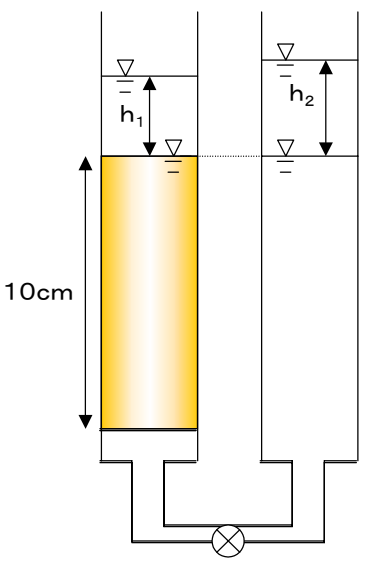

Figure 1: One-dimensional unsteady seepage flow problem
TABLE 1

INITIAL CONDITION AND BOUNDARY CONDITIONS

\begin{tabular}{|c|c|c|}
\hline & Initial Condition $(\mathrm{kPa})$ & Boundary Conditions (m) \\
\hline Case I & $\left.u\right|_{t=0}=0.15 \cdot \gamma_{w}$ & $h_{1}=0.15, \quad h_{2}=0$ \\
\hline Case II & $\left.u\right|_{t=0}=0$ & $h_{1}=0, \quad h_{2}=0.12$ \\
\hline Case III & $\left.u\right|_{t=0}=0$ & $h_{1}=0.01 \cdot t, \quad h_{2}=0$ \\
\hline Case IV & $\left.u\right|_{t=0}=0$ & $h_{1}=0, \quad h_{2}=0.01 \cdot t$ \\
\hline
\end{tabular}

TABLE 2

SOIL AND NUMERICAL PARAMETERS

\begin{tabular}{|c|c|c|c|}
\hline Newmark $\beta$ : $\beta$ & 0.3025 & Unit weight of water: $\gamma_{w}$ & $9.8 \mathrm{kN} / \mathrm{m}^{3}$ \\
\hline Newmark $\beta: \gamma$ & 0.6 & \multirow{2}{*}{$\begin{array}{l}\text { Unit weight of saturated } \\
\text { sand: } \gamma_{\text {sat }}\end{array}$} & \multirow[t]{2}{*}{$18.98 \mathrm{kN} / \mathrm{m}^{3}$} \\
\hline Reyleigh damping : $\alpha_{0}$ & 0.0 & & \\
\hline Reyleigh damping : $\alpha_{1}$ & 0.001 & Elastic bulk modulus: $\mathrm{K}$ & $1564 \mathrm{kPa}$ \\
\hline Initial void ratio: $\mathrm{e}_{0}$ & 0.772 & Elastic shear modulus: $\mathrm{G}$ & $938 \mathrm{kPa}$ \\
\hline \multicolumn{4}{|c|}{ Coefficient of consolidation: $\mathrm{c}_{\mathrm{v}}=2.87 \times 10^{-4}\left(\mathrm{~m}^{2} / \mathrm{sec}\right), \quad \mathrm{k}=1.0 \times 10^{-6}(\mathrm{~m} / \mathrm{sec})$} \\
\hline
\end{tabular}
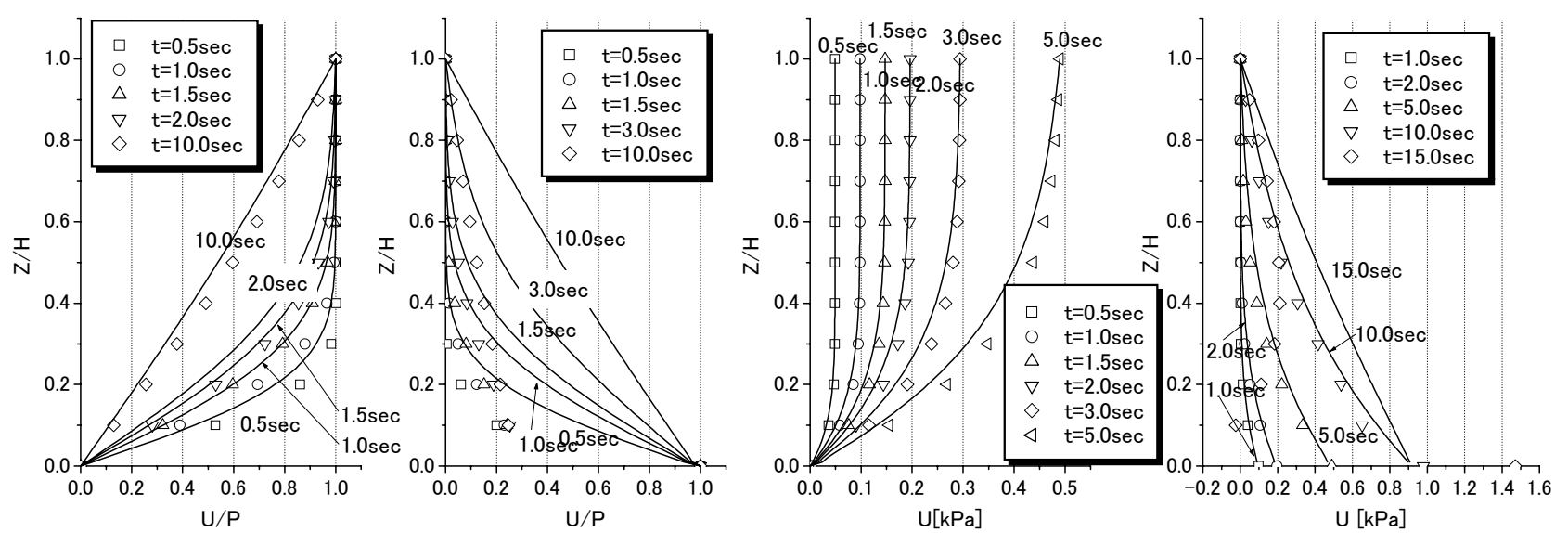

Figure 2: Analytical isochrones and numerical results

In that case, the direction of seepage force in sand column is up side. In the case of instantaneous loading, the difference of water head is previously set keeping the valve closed and then the valve is suddenly opened. In the case of increasing loading, the initial water head is same in both cylinders and then the water head in the one cylinder is gradually increased keeping the valve opened. In all cases, the one-dimensional unsteady seepage flow problems are described by the following heat conduction type partial differential equations derived from one-dimensional consolidation theory.

$$
\text { Instantaneous loading: } \frac{\partial u}{\partial t}=c_{v} \frac{\partial^{2} u}{\partial z^{2}}, \quad \text { Increasing loading: } \frac{\partial u}{\partial t}-\frac{\partial P(t)}{\partial t}=c_{v} \frac{\partial^{2} u}{\partial z^{2}}
$$

where $u$ is the excess pore water pressure, $z$ is a depth from the top surface of sand column, $c_{v}$ is the coefficient of consolidation, and $P(t)$ is the load at time $t$. The analytical solutions are obtained by solving the proper initial - boundary value problem. Table 1 shows the initial and 
boundary values for each case. Figure 2 shows the analytical isochrones obtained by equation (5) as well as the plots of computational results obtained by LIQCA-FD. Table 2 shows the used parameters for the computation. The coefficient of consolidation $c_{v}$ is equal to $k / m_{v} \gamma_{w}$, in which the coefficient of volumetric compression $m_{v}$ can be calculated by the elastic modulus listed in the table. Except for the results of Case II, the computational results can explain the analytical solutions. The results in increasing loading cases are more accurate than that in instantaneous loading cases. In Case II, it seems that the change of the excess pore pressure at bottom surface is too rapid to simulate by the finite element method with a given time step. In Case IV, the computational results obtained after 9.4 second diverged. It is adopted that the limit hydraulic gradient is 0.935 . The results by the finite element computation with LIQCA-FD well agree with analytical results of the unsteady seepage problem, in particular, in the increasing loading problem.

\section{TWO-DIMENSIONAL SEEPAGE FAILURE MODEL TEST}

The classical seepage failure problem in which the horizontal sandy ground with an embedded sheet pile is considered. Figure 3 illustrates the model test apparatus. The sandy ground model is made by water sedimentation method using Toyoura sand to set the relative density $D_{r}=60 \%$. The water head of upstream, i.e. left side from sheet pile, is gradually raised until the occurrence of seepage failure. The rate of raising the water head is $2 \mathrm{~cm} / \mathrm{min}$. Figure 4 shows the deformation pattern of sandy ground around the sheet pile with different water head difference $h$. When the water head difference reaches $17.2 \mathrm{~cm}$, the sand deposit of down stream near the sheet pile gradually heaves. The boiling of sand is observed at a water head difference of $18.5 \mathrm{~cm}$.

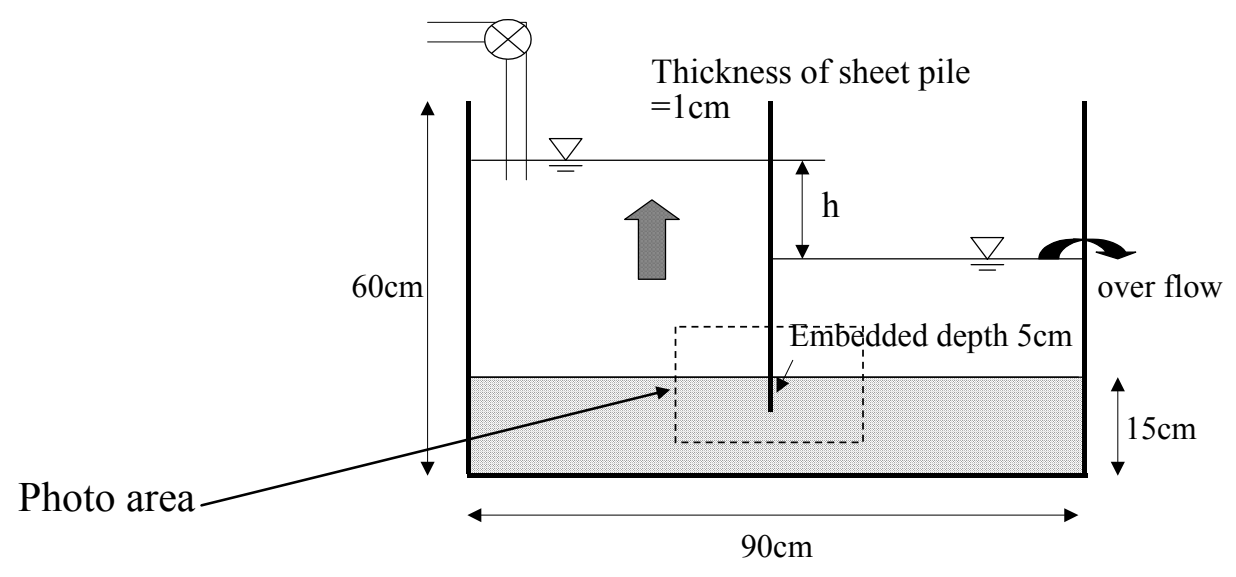

Figure 3: Model test apparatus and boundary conditions

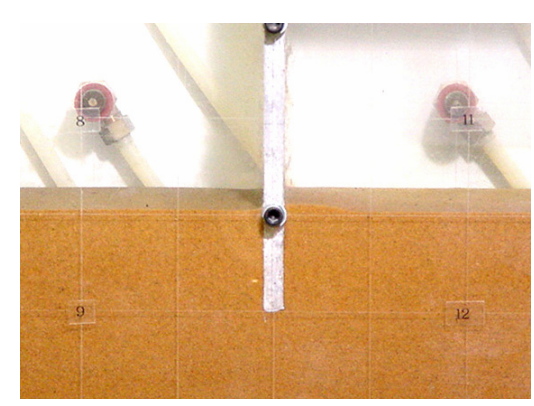

(a) $h=17.2 \mathrm{~cm}$

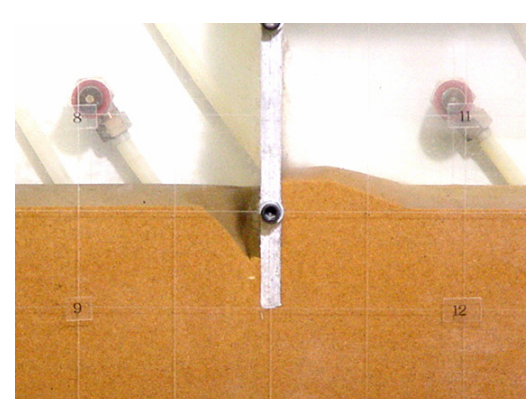

(b) $h=18.0 \mathrm{~cm}$

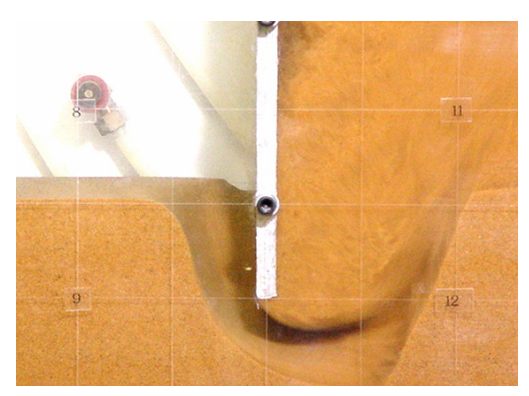

(c) $h=18.5 \mathrm{~cm}$

Figure 4: Deformation of sand deposit with different water head difference $h$ 


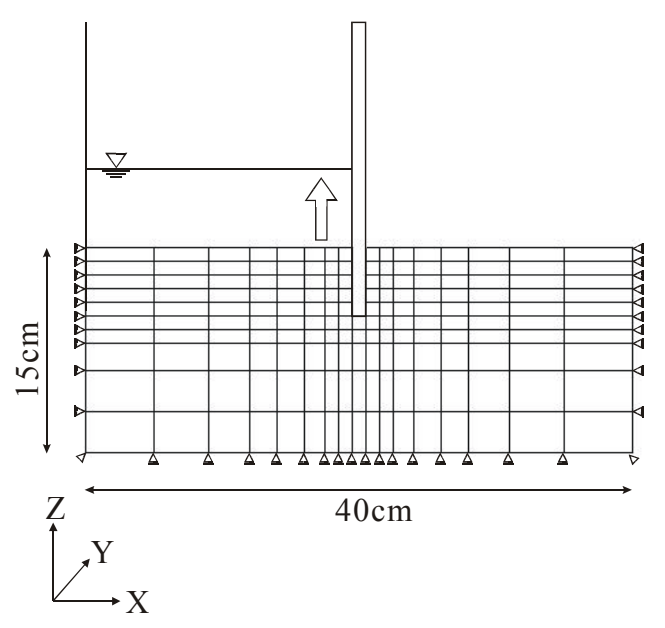

Figure 5: Finite element mesh

TABLE 3

MATERIAL PARAMETERS USED IN THE SIMULATION

\begin{tabular}{cccc}
\hline$\lambda$ & 0.02 & $B_{0}^{*}$ & 3500 \\
\hline$\kappa$ & 0.0052 & $B_{1}^{*}$ & 350 \\
\hline$v$ & 0.25 & $C_{f}^{*}$ & 2000 \\
\hline$M_{m}^{*}$ & 0.707 & $n$ & 1.5 \\
\hline$M_{f}^{*}$ & 0.990 & $\gamma_{D A r}^{P}$ & 0.004 \\
\hline$k(\mathrm{~m} / \mathrm{sec})$ & $1.0 \times 10^{-4}$ & $\gamma_{D A r}^{E}$ & 0.001 \\
\hline Refer to Oka et al. (1999) about the details of material parameters
\end{tabular}

\section{SIMULATION OF THE MODEL TEST}

Figure 5 denotes the finite element mesh used in the simulation. We applied three-dimensional liquefaction analysis method LIQCA-FD to the two-dimensional seepage failure problem, hence, only one element is used to the $\mathrm{Y}$ direction. Table 3 shows the material parameters used in the analysis. Since the cyclic elasto-plastic model proposed by Oka et al. (1999) is used, it can be reproduced that the sand deposit completely reaches to failure state or liquefaction around the sheet pile. These elasto-plastic parameters are determined by fitting the behavior of Toyoura sand ( $D_{r}=60 \%$ ) in the various cyclic simple shear tests to their simulated results (Oka et al. 1999). Figures 6, 7, and 8 show the calculated excess pore water pressure distributions, mean effective stress distributions, and relative mean effective stress ratio distributions, respectively, in the case of water head difference of $15 \mathrm{~cm}$. The relative mean effective stress ratio is defined as $1-T_{m}^{\prime} / T_{m 0}^{\prime}$, consequently the sandy ground in which relative mean effective stress ratio closes to 1 can be identified as liquefaction. From these figures, the down stream area near the sheet pile is close to liquefaction and seepage failure occurs as the water head difference increases. Figure 9 indicates the comparison between the computed deformed meshes and the observed test results near the seepage failure conditions. It should be noted that the computed deformation is twenty times exaggerated. It is, therefore, seen that the numerical results of deformation can be just qualitatively explained.

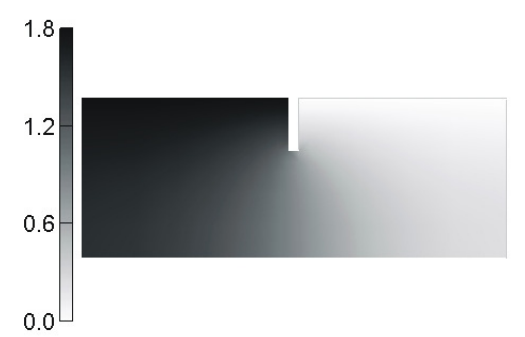

Figure 6: Excess pore water pressure distribution at $h=15 \mathrm{~cm} \quad(\mathrm{kPa})$

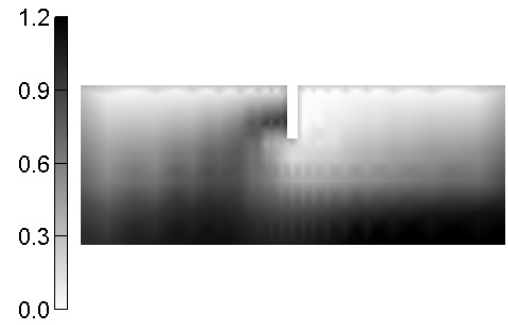

Figure 7: Mean effective stress distribution at $h=15 \mathrm{~cm} \quad(\mathrm{kPa})$

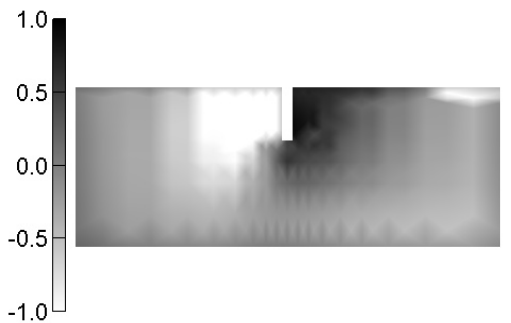

Figure 8: Relative mean effective stress ratio distribution at $h=15 \mathrm{~cm}$ 


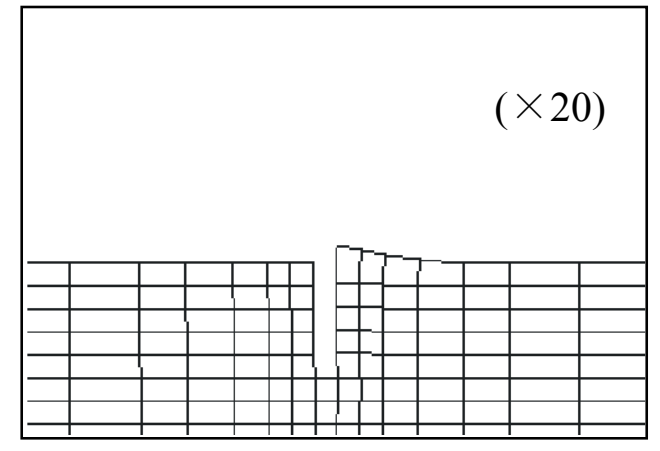

(a) Numerical simulation

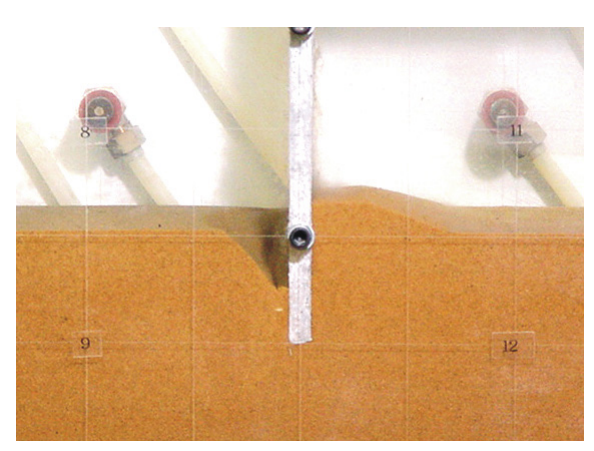

(b) Deformation in theModel test

Figure 9: Comparison between the computed deformed meshes and the observed model test results at $h=18.0 \mathrm{~cm}$

\section{CONCLUSIONS}

In the present study, the results by a liquefaction analysis method based on the finite deformation theory are compared with the analytical results of the one-dimensional unsteady seepage problem and the experimental results of two-dimensional seepage failure problem. It is found that we can quantitatively explain the changes of the pore water pressure and the mean effective stress in sand deposit until seepage failure both of one- and two-dimensional problem. In addition, deformation pattern associated with two-dimensional seepage problem can be qualitatively described. Further study is necessary for the accurate prediction of deformation.

\section{REFERENCES}

Asaoka A. and Kodaka T. (1992). Seepage failure experiments and their analyses of loose and medium dense sands, Soils and Foundations 32:3, 117-129.

Oka F., Yashima A., Kato M. and Nakajima Y. (1994a). An analysis of seepage failure using an elasto-plastic constitutive equation and its application, Journal of Geotechnical Engineering, Proc. of JSCE, 493:III-27, 127-136. (in Japanese)

Oka F., Yashima A., Shibata T., Kato M. and Uzuoka R.(1994b), FEM-FDM coupled liquefaction analysis of a porous soil using an elasto-plastic model, Applied Scientific Research, 52, 209-245.

Taguchi Y., Tateishi A., Oka F. and Yashima A.(1997), Three-dimensional liquefaction analysis method and array record simulation in Great Hanshin earthquake, Proc. 11th World Conference on Earthquake Engineering, Balkema(CD-ROM), Paper No.1042.

Oka F, Yashima A., Tateishi A., Taguchi Y. and Yamashita S. (1999), A cyclic elasto-plastic constitutive model for sand considering a plastic-strain dependence of the shear modulus, Geotechnique, 49:5, 661-680.

Oka F., Kodaka T., Koizumi T. and Sunami S. (2001), An effective stress based liquefaction analysis based on finite deformation theory, 10th IACMAG, 2, 1113 - 1116. 